\title{
$\mathrm{BLT}$ 방정식과 수치해석 기법을 이용한 전송 선로의 커플링 효과 분석
}

\begin{tabular}{|c|}
\hline 논 문 \\
\hline $61-1-17$ \\
\hline
\end{tabular}

\section{Analysis of Coupling Effects in Transmission Lines Using the BLT Equation and Numerical Methods}

\author{
두 진 경*.안 재 운 ${ }^{* *}$ 황 선 묵 ${ }^{* * *} \cdot$ 육 종 관 ${ }^{+}$
}

(Jin-Kyoung Du $\cdot$ Jae-Woon Ahn $\cdot$ Sun-Mook Hwang $\cdot$ Jong-Gwan Yook)

\begin{abstract}
The electromagnetic topology and the BLT equation has been used as useful techniques to analyze coupling effects of huge devices. But in the case of systems including complex parts, applying the BLT equation can be difficult to manifest the complex parts with analytic solutions. To resolve this problem, a numerical method can be used to parts of the whole system in advance. In this paper, a microstrip line filter is analyzed using the BLT equation combined with numerical solutions. Consequently, achieved graphs from the BLT equation show good agreements with graphs obtained using a numerical method only.
\end{abstract}

Key Words : BLT equation, Coupling effects, Electromagnetic topology, Numerical analysis

\section{1. 서 론}

IT 기술이 발달함에 따라 전자 기기의 속도는 점차 빨라 지고 기능은 더욱 복잡해지고 있으나, 이러한 고성능의 전자 기기일수록 외부로부터 침투해 들어온 신호에 의해 치명적 인 영향을 받을 수 있다. 외부로부터의 커플링 현상은 전자 기기 내부의 서로 다른 시스템 사이에서도 발생할 수 있으 며, 주변의 전자 기기로부터 방사되는 전자기파에 의해서도 발생한다. 이러한 커플링은 본래 신호의 흐름을 방해하거나 정보를 왜곡함으로써 시스템이 제대로 동작할 수 없도록 하 는데, 특히 이러한 현상을 무기에 적용한 고출력 전자파 무 기는 주변의 수많은 전자 기기를 순식간에 무력화시킬 수 있기 때문에 최근에는 전자파 무기에 의해 주요 시설에 발 생하는 커플링 효과를 분석하는 연구가 많이 진행되고 있다 [1-2]. 이로부터, 송배전선로 등 외부로 노출되어 있는 사회 간접 자본 시설은 그 영향에 더욱 취약함을 알 수 있다.

커플링 효과의 분석에는 유한요소법(Finite Element Method: FEM) 또는 유한차분시간영역법(Finite-Difference Time-Domain: FDTD)과 같은 수치해석 기법이 많이 사용 되고 있으나 비행기나 자동차, 군함 같이 파장에 비해 거대 한 크기를 가지는 물체를 해석하기에는 시간과 메모리 등의 자원이 대량으로 요구되는 단점이 있다. 이에 대한 해결책 으로서 전자기 위상기하학(Electromagnetic Topology: EMT)과 Baum-Liu-Tesche(BLT) 방정식[3-4]을 이용한 연

\footnotetext{
* 정 회 원 : 연세대 공대 전기전자공학과 박사과정

** 비 회 원 : (주)한화 전문위원

*** 정 회 원 : (주)한화

† 교신저자, 정회원 : 연세대 공대 전기전자공학과 교수

E-mail : jgyook@yonsei.ac.kr

접수일자 : 2011년 11월 4일

최종완료 : 2011년 12월 23일
}

구가 수행되어 왔는데, 이는 커다란 시스템을 여러 개의 하 위 구조로 나누어 각 단위 구조 사이에 발생하는 커플링을 분석한 후에 이들을 다시 하나로 통합하여 해석하는 방법이 다. 수치해석 기법으로 전체 시스템을 해석하는 경우와 비 교했을 때, 구조물 형태의 세밀함을 해석에 반영하는 정도는 감소하지만 해석에 필요한 시간과 메모리 자원의 양을 줄일 수 있으므로 비행체와 같이 전체 구조물의 형태를 간략화 하여 해석해도 무방한 경우에는 BLT 방정식을 효과적으로 사용할 수 있다. BLT 방정식을 사용하여 파장에 비해 거대 한 물체에 대한 커플링 효과를 분석한 연구가 해외 연구 기 관[5-7]뿐만 아니라 최근에는 국내에서도 다양하게 수행 [8-10]되고 있으며, 거대 구조 이외에 소단위 규모의 전송 선로 해석에도 $\mathrm{BLT}$ 방정식을 유용하게 적용한 연구 결과 [11-12]가 보고되었다.

이와 같이 $\mathrm{BLT}$ 방정식을 사용하여 해석할 때에는 단위 구조 사이의 커플링을 수식적으로 표현해야 하는데, 각각의 형태에 따라 포클링턴(Pocklington) 방정식 또는 그린 (Green) 함수 등이 관계식으로서 사용된다[10]. 그러나 실제 커플링 효과의 분석이 요구되는 비행기나 미사일, 자동차 등 의 내부는 단순한 구조가 아닌 여러 복잡한 구조들로 이루 어져 있으므로 $\mathrm{BLT}$ 방정식을 이용한 분석을 보다 실용적으 로 수행하기 위해서는 복잡한 내부 구조에도 적용 가능하도 록 개선하여야 하며, 이에 대한 방안으로 부분 구조에 대한 수치해석 결과를 기존의 BLT 방정식에 적용하여 전체 시스 템을 분석하는 방법이 제안되었다[13]. 본 논문에서는 이러 한 분석 방법을 간단한 마이크로스트립 라인(microstrip line) 형태의 필터(filter)에 적용해봄으로써 수식의 활용성을 검증하고자 한다. 이러한 방법이 제안된 이유는 미사일이나 비행기와 같은 거대 구조의 커플링 효과를 분석하기 위함이 므로 마이크로스트립 라인처럼 단순한 전송 선로 구조보다 는 원형 도파관과 같은 실제 비행체에 가까운 예제가 필요 


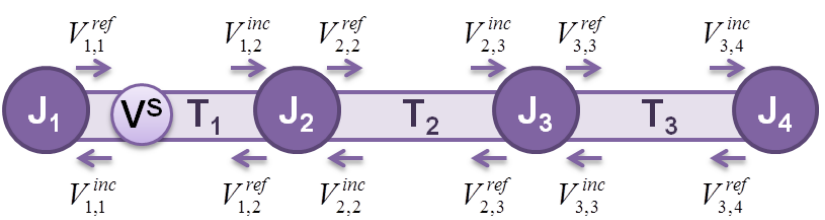

그림 $1 \mathrm{BLT}$ 방정식 구성을 위한 신호 흐름도

Fig. 1 A signal flow graph for generating the BLT equation

할 것이나, 본 논문에서는 복잡하고 큰 구조물에 대한 적용 가능성을 검증하는 사전 단계로서 비교적 간단한 전송 선로 구조를 선택하였으며, 향후에는 적용 범위를 확장하여 원형 도파관과 같이 실제 비행체와 유사한 형태에 대한 커플링 효과를 분석할 것이다. 다음의 본론에서는 $\mathrm{BLT}$ 방정식에 수치해석 결과를 적용하는 방법을 보다 상세히 다룬 후에, 마이크로스트립 라인 형태의 필터에 적용하여 분석한 결과 에 대해 설명하였다.

\section{2. 수치해석 기법이 적용된 $\mathrm{BLT}$ 방정식의 구성}

본 장에서는 부분 구조에 대해 수치해석 기법을 사용해 얻은 $S$-파라미터를 $\mathrm{BLT}$ 방정식에 적용하는 방법에 대하여 수식적으로 설명한다. BLT 방정식을 사용하기 위해서는 해 석하고자 하는 전체 시스템을 작은 단위의 하위 구조로 나 누고, 이를 하나의 튜브(tube)로 정의한다. 그리고 각 튜브의 양단에는 정션(junction)이 존재하여 서로 다른 튜브를 연결 한다. 이러한 여러 개의 튜브들, 즉 하위 구조들 중 수식적 으로 표현하기 어려운 구조에 대해서 수치해석 기법으로 분 석하고 그 결과 값을 $S$-파라미터의 형태로 얻는다면 BLT 방정식의 해당 튜브에 대한 관계식으로 대체하여 사용할 수 있다.

\section{1 기존의 BLT 방정식}

앞서 간략히 언급한 바와 같이 BLT 방정식은 전체 구조 를 여러 개의 튜브와 정션을 이용하여 표현한다. 그림 1 은 3 개의 튜브와 4 개의 정션으로 구성된 시스템의 신호 흐름도 (signal flow)를 나타낸 것이다. 여기에서 $V_{A, B}$ 는 튜브 $T_{A}$ 와 정션 $J_{B}$ 에 존재하는 전압 신호를 의미하며, $V^{i n c}$ 는 튜브로 부터 정션으로 입사하는 전압 신호를, $V^{r e f}$ 는 정션으로부터 튜브로 들어가는 전압 신호를 각각 나타낸다. 그리고 $V^{S}$ 는 외부로부터 유입된 전자기 신호에 의하여 커플링 된 전압 소스를 의미하며, 그림 1 의 경우에는 이러한 외부 소스가 튜 브 $T_{1}$ 로 유입되어 정션 $J_{1}$ 과 $J_{2}$ 에 전달된다.

시스템의 신호 흐름도를 구성한 후에는 각 튜브와 정션의 전압 신호 관계식을 이용하여 전파 행렬 (propagation matrix) $P$ 와 산란 행렬(scattering matrix) $S$ 를 각각 구성하 며[3-4], 이를 이용하여 얻은 (1)과 (2)를 조합한 (3)이 바로 $\mathrm{BLT}$ 방정식이다. [3]의 $\mathrm{BLT}$ 방정식에서 전파 행렬로 사용 한 $\Gamma$ 와 본 논문의 $P$ 는 $\Gamma=P^{-1}$ 의 관계식이 성립한다. 각각 의 전압 벡터 $V$ 와 $V^{i n c}, V^{r e f}, V^{S}$ 그리고 행렬 $P$ 와 $S$ 는 분 석하고자 하는 주파수에 대하여 각기 다른 값을 가지므로 여러 주파수에 대한 값을 하나로 묶어 표현하는 슈퍼 벡터

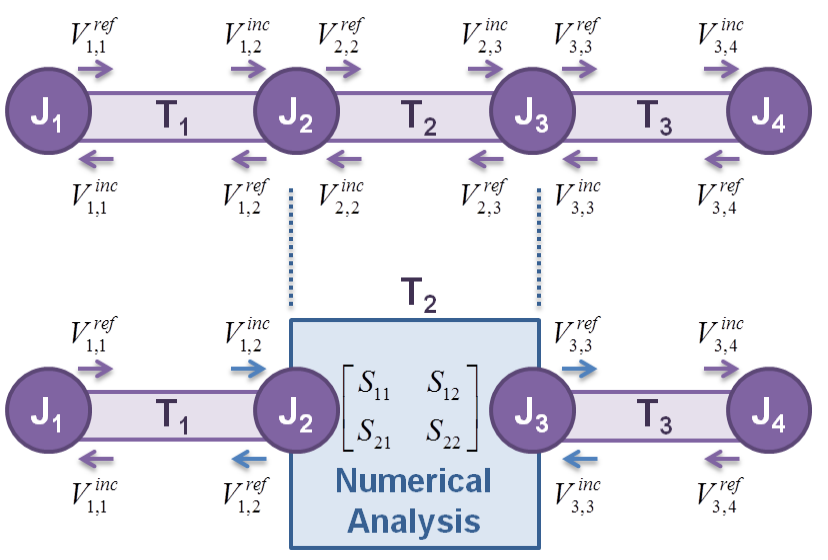

그림 2 튜브 $T_{2}$ 에 수치해석 기법을 적용하는 경우

Fig. 2 Analysis of tube $T_{2}$ using a numerical method

와 슈퍼 행렬을 사용하는데, 이를 기호 [ ]와 \{ \}로 각각 표 현한다.

$$
\begin{aligned}
{\left[V^{i n c}\right] } & =(\{U\}-\{P\} \cdot\{S\})^{-1} \cdot\left[V^{S}\right] \\
{\left[V^{r e f}\right] } & =\{S\} \cdot(\{U\}-\{P\} \cdot\{S\})^{-1} \cdot\left[V^{S}\right] \\
{[V] } & =\left[V^{i n c}\right]+\left[V^{r e f}\right] \\
& =(\{U\}+\{S\}) \cdot(\{U\}-\{P\} \cdot\{S\})^{-1} \cdot\left[V^{S}\right]
\end{aligned}
$$

\section{2 수치해석으로 얻은 결과 적용 방법}

2.1절에서 보인 바와 같이 BLT 방정식을 구성하기 위해 서는 전압 신호 사이의 관계를 모두 수식으로 표현하여야 하는데, 단위 구조의 형태가 복잡하다면 이러한 수식 표현이 어려워진다. 따라서 이에 대한 해결 방법으로, 부분 구조에 대해 수치해석 기법을 사용하고 이로부터 얻은 $S$-파라미터 를 $\mathrm{BLT}$ 방정식에 적용하는 방법이 제안되었다[13].

그림 2 는 그림 1 의 시스템에 대하여 튜브 $T_{2}$ 만을 수치해 석 기법으로 해석하는 경우이며, $V^{S}$ 는 생략하여 표현하였 다. 이 때 튜브 $T_{2}$ 가 튜브 $T_{1}$ 과 $T_{3}$ 에 연결되는 부분, 즉 정 션 $J_{2}$ 와 $J_{3}$ 이 각각 연속적인 구조라고 가정한다면 아래의 (4)가 성립한다. 이와 같은 가정 하에 정션 $J_{2}$ 와 $J_{3}$ 을 각각 port 1, port 2로 설정하고 수치해석 기법으로 얻은 $S$-파라 미터를 $S_{11}$ 과 $S_{12}, S_{21}, S_{22}$ 라고 한다면 (5)와 (6)을 얻는다. 그리고 이러한 관계식을 행렬 $P$ 와 $S$ 에 적용하면 결과적으 로 (7)과 (8)을 얻는다.

$$
\begin{aligned}
& V_{1,2}^{r e f}=V_{2,2}^{\text {inc }}, \\
& V_{2,2}^{r e f}=V_{1,2}^{\text {inc }}, \\
& V_{2,3}^{r e f}=V_{3,3}^{\text {inc }}, \\
& V_{3,3}^{r e f}=V_{2,3}^{\text {inc }}
\end{aligned}
$$




$$
\begin{aligned}
V_{2,2}^{\text {inc }} & =V_{1,2}^{\text {ref }} \\
& =S_{11} \cdot V_{1,2}^{\text {inc }}+S_{12} \cdot V_{3,3}^{\text {inc }} \\
& =S_{11} \cdot V_{2,2}^{r e f}+S_{12} \cdot V_{2,3}^{r e f} \\
V_{2,3}^{\text {inc }} & =V_{3,3}^{r e f} \\
& =S_{22} \cdot V_{3,3}^{\text {inc }}+S_{21} \cdot V_{1,2}^{\text {inc }} \\
& =S_{22} \cdot V_{2,3}^{r e f}+S_{21} \cdot V_{2,2}^{r e f} \\
P & =\left[\begin{array}{cccccc}
0 & e^{-\not \varkappa_{1}} & 0 & 0 & 0 & 0 \\
e^{-\not x_{1}} & 0 & 0 & 0 & 0 & 0 \\
0 & 0 & S_{11} & S_{12} & 0 & 0 \\
0 & 0 & S_{21} & S_{22} & 0 & 0 \\
0 & 0 & 0 & 0 & 0 & e^{-\gamma \varkappa_{3}} \\
0 & 0 & 0 & 0 & e^{-\chi_{3}} & 0
\end{array}\right] \\
S= & {\left[\begin{array}{cccccc}
\rho^{1} & 0 & 0 & 0 & 0 & 0 \\
0 & 0 & 1 & 0 & 0 & 0 \\
0 & 1 & 0 & 0 & 0 & 0 \\
0 & 0 & 0 & 0 & 1 & 0 \\
0 & 0 & 0 & 1 & 0 & 0 \\
0 & 0 & 0 & 0 & 0 & \rho^{4}
\end{array}\right] }
\end{aligned}
$$

이처럼 부분적으로 수치해석 기법을 사용하여 얻은 결과 값을 $\mathrm{BLT}$ 방정식에 적용할 수 있으며, 다음 절에서는 간단

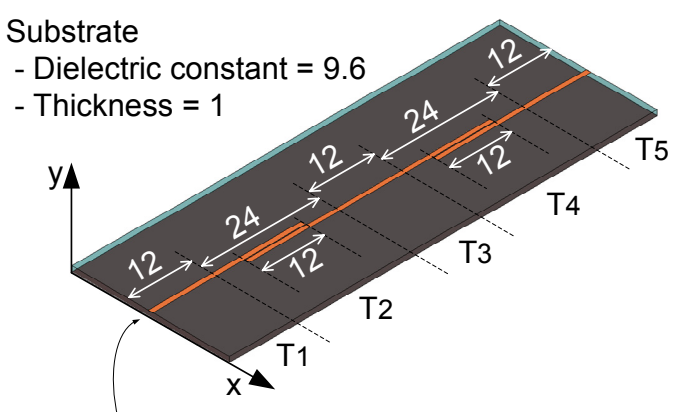

Signal line width $=0.9$

그림 3 마이크로스트립 라인 필터의 전체 구조

Fig. 3 The entire structure of a microstrip line filter

한 마이크로스트립 라인 필터에 대해 이를 적용해봄으로써 수식을 검증하였다.

\section{BLT 방정식을 이용한 마이크로스트립 라인 필터 해석}

\section{1 해석 구조 설명}

BLT 방정식을 사용하여 해석하려는 마이크로스트립 라 인 필터를 그림 3 에 나타내었다. 총 3 개의 신호선 중간에 두 번의 필터링이 발생하도록 설계하였다. 기판의 두께는 1 $\mathrm{mm}$ 이고 비유전율은 9.6 이며, 모든 신호선의 너비는 0.89 $\mathrm{mm}$ 로 동일하다. 또한, 필터링이 발생하는 부분에서 두 신호

$$
P=\left[\begin{array}{cccccccccc}
0 & e^{-\gamma L_{1}} & 0 & 0 & 0 & 0 & 0 & 0 & 0 & 0 \\
e^{-\gamma L_{1}} & 0 & 0 & 0 & 0 & 0 & 0 & 0 & 0 & 0 \\
0 & 0 & S_{11}^{2} & S_{12}^{2} & 0 & 0 & 0 & 0 & 0 & 0 \\
0 & 0 & S_{21}^{2} & S_{22}^{2} & 0 & 0 & 0 & 0 & 0 & 0 \\
0 & 0 & 0 & 0 & 0 & e^{-\gamma L_{3}} & 0 & 0 & 0 & 0 \\
0 & 0 & 0 & 0 & e^{-\gamma L_{3}} & 0 & 0 & 0 & 0 & 0 \\
0 & 0 & 0 & 0 & 0 & 0 & S_{11}^{4} & S_{12}^{4} & 0 & 0 \\
0 & 0 & 0 & 0 & 0 & 0 & S_{21}^{4} & S_{22}^{4} & 0 & 0 \\
0 & 0 & 0 & 0 & 0 & 0 & 0 & 0 & 0 & e^{-\gamma L_{5}} \\
0 & 0 & 0 & 0 & 0 & 0 & 0 & 0 & e^{-\gamma L_{5}} & 0
\end{array}\right]
$$

$$
S=\left[\begin{array}{cccccccccc}
\rho^{1} & 0 & 0 & 0 & 0 & 0 & 0 & 0 & 0 & 0 \\
0 & 0 & 1 & 0 & 0 & 0 & 0 & 0 & 0 & 0 \\
0 & 1 & 0 & 0 & 0 & 0 & 0 & 0 & 0 & 0 \\
0 & 0 & 0 & 0 & 1 & 0 & 0 & 0 & 0 & 0 \\
0 & 0 & 0 & 1 & 0 & 0 & 0 & 0 & 0 & 0 \\
0 & 0 & 0 & 0 & 0 & 0 & 1 & 0 & 0 & 0 \\
0 & 0 & 0 & 0 & 0 & 1 & 0 & 0 & 0 & 0 \\
0 & 0 & 0 & 0 & 0 & 0 & 0 & 0 & 1 & 0 \\
0 & 0 & 0 & 0 & 0 & 0 & 0 & 1 & 0 & 0 \\
0 & 0 & 0 & 0 & 0 & 0 & 0 & 0 & 0 & \rho^{6}
\end{array}\right]
$$




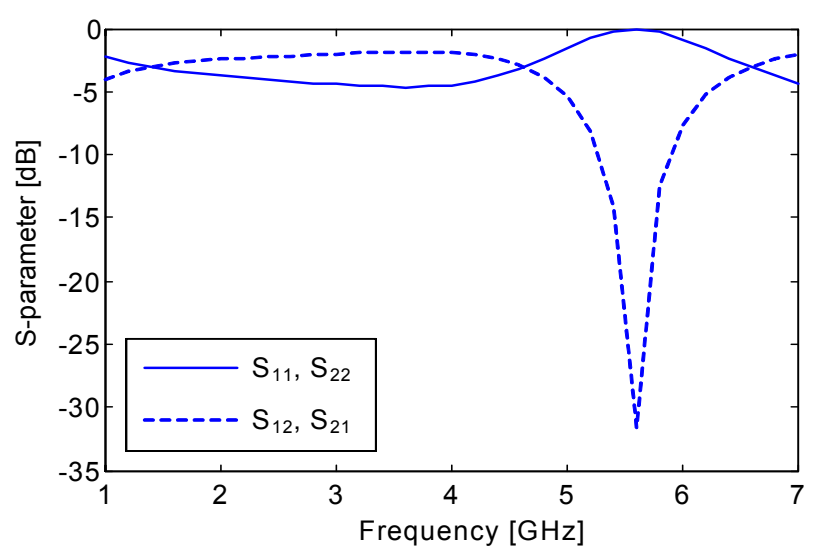

그림 4 튜브 $T_{2}$ 와 $T_{4}$ 에 대한 $\mathrm{FEM}$ 해석으로 얻은 $S$-파라미터

Fig. $4 S$-parameters of tube $T_{2}$ and $T_{4}$ obtained from FEM analysis

선 사이의 간격은 $0.1 \mathrm{~mm}$ 이며, 이 부분의 길이는 $12 \mathrm{~mm}$ 이 다. $\mathrm{BLT}$ 방정식으로 해석하기 위해 전체 구조를 5 개의 하 위 구조로 나누었으며, 이로 인해 5 개의 튜브와 6 개의 정션 이 생성된다. 5 개의 튜브 중 튜브 $T_{2}$ 와 $T_{4}$ 가 필터링이 발생 하는 구조에 해당하며, 나머지 튜브 $T_{1}, T_{3}$, 그리고 $T_{5}$ 는 직 선 구조의 전송 선로이다. 이 중에 튜브 $T_{2}$ 와 $T_{4}$ 에 대해서 만 먼저 수치해석 기법 중 하나인 $\mathrm{FEM}$ 으로 해석 하고, 이 로써 얻어진 $S$-파라미터를 $\mathrm{BLT}$ 방정식에 적용한다. $\mathrm{FEM}$ 해석으로 얻은 $S$-파라미터를 그림 4 에 그래프로 나타내었으 며, 주파수 $5.6 \mathrm{GHz}$ 를 중심으로 가장 많은 신호가 필터링 됨을 알 수 있다. 이 때 튜브 $T_{2}$ 와 $T_{4}$ 는 서로 동일한 구조 이므로 $\mathrm{FEM}$ 해석으로 분석한 결과 역시 동일하다.

\subsection{BLT 방정식의 구성}

$\mathrm{FEM}$ 해석으로 얻은 $S$-파라미터 값을 $\mathrm{BLT}$ 방정식의 행 렬 $P$ 와 $S$ 에 대입하면 (9)와 (10)이 된다. 총 튜브의 개수가 5 개 이므로 행렬 $P$ 와 $S$ 의 크기는 $10 \times 10$ 이 되며, 수식에서 사용된 $L_{1}, L_{3}$, 그리고 $L_{5}$ 는 모두 $12 \mathrm{~mm}$ 로 동일하다. 전체 시스템의 양단을 50 옴으로 매칭 했을 때, $\rho^{1}$ 과 $\rho^{6}$ 은 1 의 값 을 가진다. 이와 같이 구성한 행렬을 (3)에 대입함으로써 전 압 신호 $V$ 를 계산할 수 있다.

\section{3 결과 그래프의 비교}

마이크로스트립 라인 필터에 대하여 $\mathrm{BLT}$ 방정식을 이용 한 결과와 $\mathrm{FEM}$ 해석 방법만을 사용하여 얻은 결과를 그림 5 에 그래프로 비교하였다. 주파수 $5.6 \mathrm{GHz}$ 에서 필터링이 발 생하는 단위 구조를 직렬로 연결하였으므로, 그림 4 와 비교 하였을 때 동일한 $5.6 \mathrm{GHz}$ 주파수 부근에서의 필터링 현상 은 더욱 커졌으며, 전체 길이가 커짐에 따라 추가적인 공진 특성이 발생하였다. 수치해석 기법을 적용한 BLT 방정식으 로 계산한 결과 그래프는 $\mathrm{FEM}$ 해석 방법으로 얻은 결과와 비교했을 때 매우 일치한다.

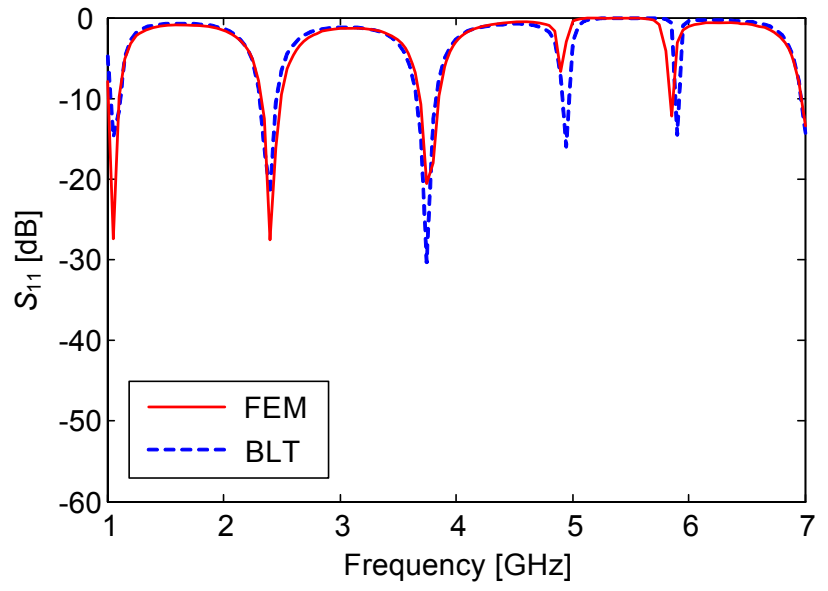

(a)

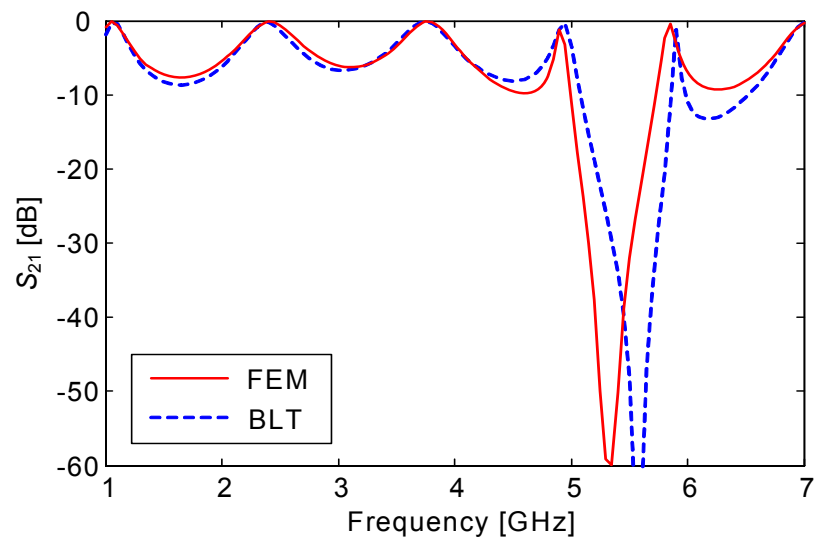

(b)

그림 $5 \mathrm{BLT}$ 방정식과 $\mathrm{FEM}$ 해석 결과 비교

Fig. 5 Comparison of results from the BLT equation and FEM analysis

\section{4. 결 론}

본 논문에서는 전체 중 일부에만 수치해석 기법으로 계산 한 결과를 BLT 방정식에 적용하는 방법에 대하여 수식적으 로 설명하였으며, 이를 마이크로스트립 라인 필터에 적 용하였다. 이로써 얻은 결과와 수치해석 계산 결과를 비교 하였을 때, 매우 유사함을 확인하였다. 이는 BLT 방정식을 사용하여 해석 가능한 구조물의 범위를 좀 더 복잡한 형태 의 구조물까지 확대하였다는 점에서 의미 있는 결과라 할 수 있다. 본 논문에서는 마이크로스트립 라인 형태의 전송 선로 구조를 바탕으로 수식을 검증하였으며, 향후에는 원형 도파관과 같이 실제 비행체와 유사한 형태의 시스템에 대한 커플링 효과를 분석할 것이다.

\section{감사의 글}

본 논문은 (주)한화 지원에 의한 연구 결과입니다. 


\section{참 고 문 헌}

[1] M. Backstrom and J. Loren, "Microwave coupling into a generic object. Properties of measured angular receiving pattern and its significance for testing", IEEE Int. Zurich Symposium on EMC, vol. 2, pp. 1227-1232, 2001.

[2] I. Junqua, L. Guibert, and J. -P. Parmantier, "Assessment of high-frequency coupling in a generic object by the power balance method", IEEE Int. Zurich Symposium on EMC Zurich, pp. 397-400, 2007.

[3] F. M. Tesche and C. M. Butler, "On the addition of EM field propagation and coupling effects in the BLT equation," Interaction Note, no. 588, December 2003.

[4] F. M. Tesche, J. Keen and C. M. Butler, "Example of the use of the BLT equation for EM field propagation and coupling calculations," Interaction Note, no. 591, August 2004.

[5] F. M. Tesche, "Development and use of the BLT equation in the time domain as applied to a coaxial cable," IEEE Trans. Electromagn. Compat., vol. 49, no. 1, pp. 3-11, February 2007.

[6] Ying Li, Gunyan Ni, Jianshu Luo, Gaosheng Li and Zipeng Zhao, "The terminal responses of the two-wire line in cavities with multi-apertures based on topological decomposition and method of moments," IEEE Int. Symposium on Antennas Propagation and EM Theory (ISAPE), pp. 888-891, 2010.

[7] Ying Li, Jianshu Luo, Guyan Ni and Jiyuan Shi, "Electromagnetic topology analysis to coupling wires enclosed in cavities with apertures," Mathematical Problems in Engineering, vol. 2010, article ID 209591, pp. 1-11, 2010.

[8] 강원준, 이비오, 문상곤, 김준호, 정용식, “BLT 방정식 을 이용하여 사각 aperture 사이를 통과한 고출력 전자 파가 공진기 내부에 미치는 영향에 관한 연구, 대한전 기학회 하계학술대회 논문집, pp. 1539-1540, 2010년 7 월.

[9] 강원준, 문상곤, 김준호, 천창율, 정용식, "BLT 방정식 을 이용한 고출력 전자파가 고주파 회로에 미치는 영 향에 관한 연구," 한국통신학회논문지, 제 35 권, 10 호, pp. 1520-1525, 2010년 10월.

[10] 이윤주, "BLT 방정식을 이용한 고출력 전자파 펄스의 효과도 연구," 광운대학교 석사학위논문, 2007년 8월.

[11] 박윤미, 황세훈, 이정엽, 정현교, "Electromagnetic Topology(EMT) 기법을 이용한 Printed Circuit Boards(PCBs) 기판 해석," 2006년도 한국정보통신설비 학회 하계학술대회 논문집, pp. 170-174, 2006년 8월.

[12] 황세훈, 박윤미, 정현교, "BLT 방정식을 이용한 RF 검파 회로 해석," 전기학회논문지, 제 56 권, 9호, pp. 1643-1647, 2007년 9월.

[13] 두진경, 현세영, 안재운, 황선묵, 육종관, "수치해석 기 법과 BLT 방정식을 이용한 커플링 효과 분석,” 한국전 자파학회 종합학술발표회, vol. 21, no. 1, 2011년 11월.
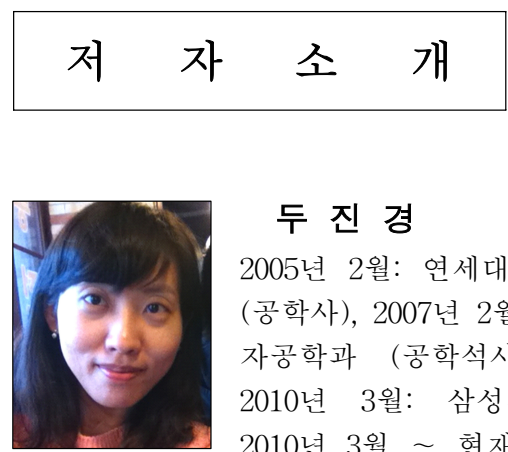

\section{두 진 경}

2005년 2월: 연세대학교 전기전자공학과 (공학사), 2007년 2월: 연세대학교 전기전 자공학과 (공학석사), 2007년 2월 2010년 3월: 삼성전자 DMC 연구소, 2010년 3월 현재: 연세 대학교 전기전 자공학과 박사과정

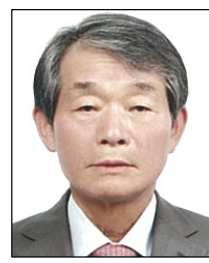

\section{안 재 운}

1949년: 6월 27일 생

1974년: 서강대학교 물리학과 (학사) 1984년: 한남대학교 물리학과 (석사) 1989년: 충남대학교 물리학과 (박사) 1976년 2010년: 국방과학연구소 2010년 현재: (주)한화 전문위원

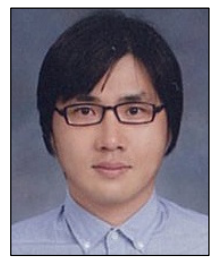

\section{황 선 묵}

1976년: 5월 2일 생

2003년: 원광대학교 전기공학과 (학사) 2005년: 인하대학교 전기공학과 (석사) 2010년: 인하대학교 전기공학과 (박사) 2010년 현재: (주)한화

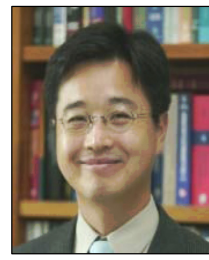

육 종 관

1987년 2월: 연세대학교 전자공학과 (공 학사), 1989년 2월: 연세 대학교 전자공학 과 (공학석사), 1996년 12월: 미국 University of Michigan 전기전자공학과 (공학박사), 1997년 1월 1998년 9월: 미국 University of Michigan Research Fellow, 1998년 10월 1999년 2월: 미국 Qualcomm Inc. Senior Engineer, 1999년 3월 2000년 2월: 광주과학기 술원 조교수, 2000년 3월 2003년 2월: 연세대학교 전기 전자공학과 조교수, 2003년 3월 2008년 8월: 연세대학 교 전기전자공학과 부교수, 2008년 9월 현재: 연세대학 교 전기전자공학과 교수

[주 관심분야] 수치해석, 바이오센서, 마이크로파구조 해 석 및 설계, $\mathrm{RF} \mathrm{MEMS}$, 박막공진구조, $\mathrm{EMC}$ 등 